\title{
Developmental instability in wild Nigerian olive baboons (Papio anubis)
}

\author{
Kara C Hoover ${ }^{\text {Corresp., 1, } 2 \text {, Emily Gelipter }{ }^{3} \text {, Volker Sommer }}{ }^{4,5}$, Kris Kovarovic ${ }^{3}$ \\ 1 Department of Anthropology, University of Alaska Fairbanks, Fairbanks, AK, United States of America \\ 2 Department of Biochemistry and Molecular Biology, University of Alaska - Fairbanks, Fairbanks, AK, United States of America \\ 3 Department of Anthropology, Durham University, Durham, United Kingdom \\ ${ }^{4}$ Gashaka Primate Project, Serti, Taraba, Nigeria \\ 5 Department of Anthropology, University College London, University of London, London, United Kingdom \\ Corresponding Author: Kara C Hoover \\ Email address: kchoover@alaska.edu
}

Background. Developmental instability in archaeological samples can be detected through analysis of skeletal and dental remains. During life, disruptions to biological internal homeostasis that occur during growth and development redirect bodily resources to returning to homeostasis and away from normal processes such as symmetrical development. Because dental enamel does not remodel in life, any deviations from normal development are left behind. Even subtle disturbances to developmental trajectory may be detected in asymmetrical development of traits, specifically a random variation in sides termed fluctuating asymmetry. Human dental fluctuating asymmetry studies are common, but here we investigate the permanent dentition of a non-human primate Papio anubis, for potential fluctuating asymmetry relative to sex, weaning, and reproductive maturity. The sample stems from an outlier population that lives in the wettest and most humid habitat of any studied baboon group. Methods. The skulls of adult baboons were collected after their natural death in Gashaka Gumti National Park, Nigeria. The permanent dentition of antimeric teeth (paired) were measured for maximum length and breadth using standard methods. The metrics were analyzed to assess the presence of fluctuating asymmetry in adult permanent mandibular and maxillary dentition. Measurement error and other forms of asymmetry (antisymmetry, directional asymmetry) were considered and dental measures expressing true fluctuating asymmetry were used to address three research questions. Results. Males exhibit greater fluctuating asymmetry than females, suggesting that males experience greater overall instability during the developmental period. While weaning is not more stressful than other life history stages for males and females (using the first molar fluctuating asymmetry index as a proxy compared to other teeth), it is more stressful for females than males. Reproduction is also not more stressful than other life 
history stages for males and females (using the third molar fluctuating asymmetry index as a proxy compared to other teeth), but it is more stressful for males than females. We explore possible explanations for these findings in the discussion. 


\section{MANUSCRIPT TITLE}

Developmental instability in wild Nigerian olive baboons (Papio anubis)

K.C. Hoover ${ }^{1}$, E. Gelipter ${ }^{2} \&$ V. Sommer ${ }^{3,4}$, K. Kovarovic ${ }^{2 *}$

${ }^{1}$ Department of Anthropology, University of Alaska Fairbanks, 1790 Tanana Loop, Fairbanks, AK 99775, USA

2 Department of Anthropology, Durham University, Dawson Building, South Road, Durham, DH1 3LE, UK

${ }^{3}$ Department of Anthropology, University College London, 14 Taviton Street, London, WC1H OBW, UK

${ }^{4}$ Gashaka Primate Project, 663001 Serti, Taraba, Nigeria

Corresponding author:

Kara C. Hoover

1790 Tanana Loop, Fairbanks, Alaska, 99775, USA

Email address: kchoover@alaska.edu

\section{ABSTRACT}

Background. Developmental instability in archaeological samples can be detected through analysis of skeletal and dental remains. During life, disruptions to biological internal homeostasis that occur during growth and development redirect bodily resources to returning to homeostasis and away from normal processes such as symmetrical development. Because dental enamel does not remodel in life, any deviations from normal development are left behind. Even subtle disturbances to developmental trajectory may be detected in asymmetrical development of traits, specifically a random variation in sides termed fluctuating asymmetry. Human dental fluctuating asymmetry studies are common, but here we investigate the permanent dentition of a non-human primate Papio anubis, for potential fluctuating asymmetry relative to sex, weaning, and reproductive maturity. The sample stems is from an outlier baboon group in terms of habitatthe wettest and most humid of any studied baboon group.

Methods. The skulls of adult baboons were collected after their natural death in Gashaka Gumti National Park, Nigeria. The permanent dentition of antimeric teeth (paired) were measured for maximum length and breadth using standard methods. The metrics were analyzed to assess the presence of fluctuating asymmetry in adult permanent mandibular and maxillary dentition. Measurement error and other forms of asymmetry (antisymmetry, directional asymmetry) were considered and dental measures expressing true fluctuating asymmetry were used to address three research questions.

Results. Males exhibit greater fluctuating asymmetry than females, suggesting that males experience greater overall instability during the developmental period. While weaning is not more stressful than other life history stages for males and females (using the first molar fluctuating asymmetry index as a proxy compared to other teeth), it is more stressful for females than males. Reproduction is also not more stressful than other life history stages for males and females (using the third molar fluctuating asymmetry index as a proxy compared to other teeth), 
47 but it is more stressful for males than females. We explore possible explanations for these 48 findings in the discussion.

49 
Papio (baboons), one of the most intensively studied primate taxa, inhabit a wide range of habitats across Africa. Most troops inhabit dry, open savanna in East and South Africa, while habitats that include forests are rare. Our study focuses on a sample of olive baboons in Gashaka Gumti National Park in northeastern Nigeria. These monkeys are outliers in terms of geography, climate and local environment, inhabiting the wettest and most humid habitat of any studied group (Sommer \& Ross 2011). Compared to savanna-dwelling baboons, their troop sizes are significantly smaller (Higham et al. 2009), possibly because forest fruits occur in clumped patches that may be difficult for larger groups to exploit. Additionally, many troops across the park raid maize and other agricultural crops to varying extents (Warren et al. 2011). These combined factors have implications for reproduction, life history and survival. For example, inter-birth intervals are longer here than elsewhere (Ross et al. 2011), and crop-raiding troops have both higher energy intake and reproductive success rates (Lodge et al. 2013).

64

65

66

67

68

69

A study of fecal glucocorticoid in Gashaka Gumti female baboons suggests they experience unusual amounts of thermoregulatory and nutritional stress throughout their lives, and this stress varies seasonally relative to rainfall and food availability (MacLarnon et al. 2015). No data are yet available on stress in male baboons. Permanent teeth develop in utero and record interruptions to growth and development during periods of developmental instability, which may leave permanent marks in the teeth such as fluctuating asymmetry (FA) (Van Valen 1962), dental enamel defects (Sarnat \& Schour 1942; Sarnat \& Schour 1941), and variation in molar cusp morphology (Corruccini \& Potter 1981; Riga et al. 2014). There is no correlation between dental enamel defects and FA in either archaeological samples (Hoover et al. 2005) or twin studies (Corruccini et al. 2005). Enamel defects may be better at recording nutritional stress due to their association with famine (Zhou \& Corruccini 1998) and weaning (Katzenberg et al. 1996; Ungar et al. 2017), but FA is an established proxy for and a broader signal of developmental instability, which may arise from external factors (e.g., climate change, resource shifts) and intrinsic ones (e.g., genetic buffering) (see Markow 1994; Polak 2003) (Frederick \& Gallup Jr. 2007; Hoover \& Hudson 2016; Leamy \& Klingenberg 2005).

FA is manifest in paired traits as non-directional deviations from perfect symmetry with equal mean development on both sides (Van Valen 1962). The underlying biological theory behind FA as a proxy for developmental instability is allied with concepts of homeostasis and canalization. During growth and development, traits may canalize (reach their final form) in an internal environment where disruptive stochastic processes (developmental noise) and the capacity to resist disruption (developmental stability or homeostasis) become unbalanced (Waddington 1942). The result is non-directional bilateral variation of traits (Van Valen 1962). These minor deviations from normal growth can be measured by variance across the midline of traits (Van Valen 1962). Thus, presence and degree of FA reflect an individual's ability to canalize a trait despite genetic and/or environmental stresses that disrupt the normal phenotypic trajectory.

Because primates have longer developmental stages compared to most other mammals in which they can record periods of instability in the hard tissues of the body (Gingerich \& Schoeninger 1979) and the development of molars overlaps in time with the life history events of interest

95 (weaning, reproductive maturity) (Fortman et al. 2002; Hlusko \& Mahaney 2009; Phillips- 
96 Conroy \& Jolly 1988), we have an opportunity to identify if there are peaks of instability

97 associated with specific developmental ages. Weaning, for example, occurs during the

98 developmental window of the first molar and is associated with increased dental stress markers

99 in both human and non-human primates (Kelley \& Schwartz 2010; Smith et al. 2013). In the case

100 of weaning and, presumably, other stresses differences exist between captive groups and those in

101 the wild, where developmental delay is common due to greater variance in environmental stress

102 (Zihlman et al. 2004). In nonhuman primates, most published data are neither collected on

103 dentition nor used to examine developmental differences based on sex or life history (Atkinson et

104 al. 2016; Boulton \& Ross 2013; Hallgrimsson 1993; Leigh \& Cheverud 1991; Little et al. 2012;

105 Newell-Morris et al. 1989; Reeves et al. 2016; Sefcek \& King 2007; Waitt \& Little 2006;

106 Willmore et al. 2005).

107

108

109

110

A few studies examining FA in the dentition of nonhuman primates have suggested that traits under sexual selection exhibit greater asymmetry, meaning that they are more susceptible to developmental stress (Manning \& Chamberlain 1993; Manning \& Chamberlain 1994). Human studies, however, have not indicated a clear signal of sex-based differences in FA (e.g., Garn et al. 1965; Harris \& Nweeia 1980; Kieser et al. 1986; Perzigian 1981). Because humans exhibit greater FA than other apes (Frederick \& Gallup Jr. 2007), we need a wider comparative dataset on nonhuman primate FA to understand the range of its manifestation across species and how it explains sex differences developmental instability due to life history, habitat and social system variation. If we can identify a primate-wide pattern to FA (starting with this study and continuing with others), we will then know to either build hypotheses based on primate-wide trends in FA (in the absence of data on a particular species, for example) or to build hypotheses relative to a species of interest. We contribute the first data on dental FA in baboons and answer the following life history questions:

1. Is there a difference in developmental instability based on sex? Gashaka Gumti baboons live at the edge of their species' geographic and ecological range (Sommer \& Ross 2011) and high levels of stress have been reported in adult and subadult females, as measured by fecal glucocorticoid (MacLarnon et al. 2015). There are no comparative data available for males and the limited data in nonhuman primate dental FA suggest that traits under sexual selection in both males and females are more vulnerable to FA (Manning \& Chamberlain 1993; Manning \& Chamberlain 1994), so we do not have an expectation.

a. Hypothesis: There are no differences in FA between the sexes.

2. Is weaning a stressful time compared to other developmental stages? In baboons, suckling ceases around 15 months; this is prior to the eruption of the first molar, which is estimated to occur around 19.5 months (Dirks \& Bowman 2007). This suggests that the first molar will be diagnostic in answering this question. The null hypothesis is that there is no difference between the FA index for first molars and the FA index for all remaining teeth. Because weaning stress has been previously reported in baboons (Dirks et al. 2002; Rhine et al. 1985), we expect that first molar indices will have significantly higher FA index than any of the remaining variables.

a. Hypothesis: FA values for first molars are higher than FA values for other teeth.

3. Are there sex-based differences in reproductive stress? In baboons, menarche begins around 4.3 years and first reproduction at 6.1 years, both of which are prior to the eruption of the third molar at approximately 6.8 years of age (Dirks \& Bowman 2007). This suggests the third molars will be diagnostic in answering this question. Given that 
142

143

144

145

146

147

148

149

150

151

152

153

154

155

156

157

158

159

160

161

162

163

164

165

166

167

168

169

170

171

172

173

174

175

176

177

178

179

180

181

182

183

184

185

186

187

sexually selected traits may be more susceptible to environmental stress (Manning \& Chamberlain 1994) and because reproductive stress is particularly high in females due to extra demand on resources, we expect female third molars will exhibit greater FA than male third molars.

a. Hypothesis: FA values for female third molars are higher than those for males.

\section{MATERIALS}

We analyzed data collected from olive baboons (Papio anubis) inhabiting Gashaka Gumti National Park $\left(06^{\circ} 55^{\prime}-08^{\circ} 13^{\prime} \mathrm{N}\right.$ and $\left.011^{\circ} 13^{\prime}-012^{\circ} 11^{\prime} \mathrm{E}\right)$ in northeastern Nigeria. Permits for research at Gashaka Gumti National Park were awarded (VS) by the Nigeria National Park Service (NPH/GEN/378/V/504). The reserve extends over $6731 \mathrm{~km}^{2}$ and represents the northern edge of the Gulf of Guinea forests and the Cameroonian Highlands, with the highest peak rising to $2416 \mathrm{~m}$ (Sommer \& Ross 2011). The park is surrounded by villages that practice subsistence farming and includes various enclaves inhabited mainly by settled Fulani cattle herders. GGNP baboons live close to the southern edge of the western biogeographical distribution of the species (Zinner et al. 2011). Baboons are replaced by large forest-dwelling monkeys (mainly drills), a short distance from the park to the south.

In GGNP, pronounced annual wet and dry seasons correspond with fluctuations in temperature and humidity (Sommer \& Ross 2011). Based on weather station data for two study sites collected from 2000-2014 (Kwano at $583 \mathrm{~m}$ above sea level and Gamgam at $320 \mathrm{~m}$ above sea level), mean minimum temperature is $20.9^{\circ} \mathrm{C}$ and mean maximum $32.5^{\circ} \mathrm{C}$. Five months with very little or no rainfall are followed by heavy downpours from mid-April to mid-November that constitute $96.3 \%$ of all precipitation (annual mean $1945 \mathrm{~mm}$, range 1681-2337 mm). Among baboon field sites, GGNP is an extreme outlier with regards to rainfall, representing the wettest of all baboon study sites to date (Higham et al. 2009).

Our study sample is from baboon skulls that were delivered to the Gashaka Primate Project research station at Kwano by locals and park rangers between 2008 and 2013. The majority were found opportunistically while working in fields or during ranger patrols. Skulls were not accepted if there was evidence (e.g., bullet holes) that the animals had been killed by humans (which is illegal inside the park). Thus, our sample represents a natural death sample. Informal assessments of weathering on bone in the field indicated bones were at weathering stages $0-2$, which suggests the material was deposited over approximately 6 years (Behrensmeyer 1978). The skulls originated from six localities within GGNP or its buffer zone- the villages of Bodel, Mayo Yum, Gashaka, Selbe, Filinga, as well as the abandoned settlement of Yakuba. Stretching across a corridor of ca. 50 × $30 \mathrm{~km}$, these $1500 \mathrm{~km}^{2}$ are colonized by a single baboon group, which inhabits the park's Southern Gashaka sector (Higham et al. 2009; Ross et al. 2011; Warren et al. 2011), where the vegetation is a mosaic of montane, submontane, lowland and riverine gallery forest with some proportions of Guinea woodland-savannah and grassland (Adanu et al. 2011). Troop sizes average 21 individuals, which typically include five adult females, three adult males, and offspring that are born throughout the year (the average number of males and subadults has not been reported) (Higham et al. 2009; Jesus 2019). Most crania were found in the vicinity of human dwellings where they are more likely to be recovered but their locations suggest that all skulls stem from troops that engaged in crop-raiding to some extent. The single

Peer) reviewing PDF | (2021:02:58413:1:1:NEW 28 Jun 2021) 
188 exception is one female skull, assumed to have been philopatric, which was found many

189 kilometers away from the nearest cultivated fields and is not likely a crop-raider.

190

191

192

193

194

195

196

197

198

199

200

201

202

203

204

205

206

207

208

209

210

211

212

213

214

215

216

217

218

219

220

221

222

223

224

225

226

227

228

229

230

231

232

233

Each cranium was soaked for one day in a denture-cleansing powder solution to remove debris, given a field accession number, and stored in a plastic or metal box. As of April 2013, the collection comprised 111 skulls, including both adults and subadults. After excluding subadults, unprovenanced females, and specimens displaying extensive wear, damage, or a significant lack of antimeric teeth, an analytical sample of 81 individuals with antimeric tooth pairs remained. This study sample includes 43 adult males and 38 adult females.

\section{METHODS}

Data Sharing. Data, scripts, and preliminary analysis outputs (e.g., distribution testing, outlier tests, scatterplots) are available at Github: https://github.com/kchoover14/BaboonStress.

Age and sex estimation. Age was assessed using the developmental stage of each tooth (e.g. unerupted, emerging or in occlusion) and the development of the basilar suture (Kahumbu \& Eley 1991; Reed 1973). Adults are defined by full occlusion including the third molarsubadults demonstrate variable eruption but may have a full complement of permanent dentition in occlusion, with the exception of third molars. Sex was assessed visually in adults on the basis of overall skull size, robusticity, size of canines or canine orifice, and other known dimorphic features that are easily observed (Leigh \& Cheverud 1991; Singleton 2002; Singleton et al. 2017).

Data collection. Standard maximum length and breadth measurements for bilophodont primates (Swindler 2002) were taken 10 times (EG) on the permanent dentition of adult mandibular and maxillary premolar and molar teeth using Mitutoyo digital calipers - replicate measurements are used to assess the impact of measurement error (ME) on FA (see Choosing Replicates). The final dataset consisted of a maximum of nine variables per individual (we did not collect data on the maxillary third premolar due canine honing). Because some individuals were missing teeth or exhibited traits that precluded measurement. (e.g., cracked crowns, wear, poor preservation), data collection on all nine variables was not always possible for each individual.

Choosing Replicates. Because measurement error is a component of any metric value, an analysis of FA must consider the contribution of ME to FA. We had the luxury and burden of ten replicates for each trait-luxury because most studies take 2-3 replicates and burden because ten is an unwieldy number for analysis. Replicate measures were taken over a period of time with breaks between each data collection trial. Early trials of data collection may contain more ME due to a lack of familiarity with the teeth but later trials may contain more ME due to data collection fatigue. Thus, we assessed ME across sets of replicates (Table 1) to determine the minimum number of replicates with the lowest ME. ME, as a percentage of between-sides difference attributable to ME (Palmer 1994), was calculated in the FA worksheet and uses the ME3 formula which is a descriptor of ME independent of units of measurements (Palmer 1994; Palmer \& Strobeck 1986; Palmer \& Strobeck 2003a). The full set of 10 replicates had the lowest mean ME (8\%) but with a wide range (18\%). These ME values are high for FA but can be reduced after excluding individual datum that fail the data inspection tests for outliers.

Peer] reviewing PDF | (2021:02:58413:1:1:NEW 28 Jun 2021) 
234

235

236

237

238

239

240

241

242

243

244

245

246

247

248

249

250

251

252

253

254

255

256

257

258

259

260

261

262

263

264

265

266

267

268

269

270

271

272

273

274

275

276

277

278
Table 1: ME summary by replicate set

Statistical Methods-Confounding Factors Affecting FA. Estimates of FA may be confounded by a variety of factors including bad raw measurements, high ME, aberrant individuals, directional asymmetry, antisymmetry, and trait size dependency (Palmer \& Strobeck 2003a). The data repository contains a step-by-step analysis of all factors affecting FA in this dataset and the results of various tests (Palmer \& Strobeck 2003b) and is only briefly discussed here. Directional asymmetry may indicate biomechanical wear or side preference (such as handedness in humans) and is identified by having a significant skew (Palmer \& Strobeck 1986; Palmer \& Strobeck 1992). Antisymmetry may indicate a genetically controlled asymmetry (e.g., one over-sized signalling claw in male fiddler crabs) that is randomly distributed between sides and is identified by having a platykurtic (broad-peaked) or bimodal distribution (Palmer \& Strobeck 1986). Directional asymmetry and antisymmetry are both assessed through skew and kurtosis statistics that describe the distribution of the observed data (Palmer \& Strobeck 1992). Trait size variation also conflates measures of FA and is tested through the use of data visualization methods and statistical tests for outlier presence. Trait size dependency is a particular issue because FA may be different across traits within a species or the same trait across species (Palmer \& Strobeck 2003a) and can be tested by correlation between average trait size and average side difference.

DA was high in the sample; we have no obvious explanation for this, but it may be caused by chewing side preference (Martinez-Gomis et al. 2009; Nissan et al. 2004). Some mammal species are known to have side-specific chewing preferences, such as horses (Parés Casanova \& Morros 2014) and goats (Parés Casanova et al. 2018). However, this has not been definitively demonstrated in non-human primates, with the exception of some prosimians where side preference has been shown at the level of the individual (Stafford et al. 1993). Interstitial wear impacts on length measurements, so if the baboons in our study sample had a specific side preference, we would expect to see greater DA in length measurements compared to breadth, which is indeed what we see in our data. Irrespective of the mechanism underlying this, due to high DA, four variables had to be eliminated: female mandibular first and second molar lengths, and male mandibular first and second molar lengths).

Due to trait size dependency, one variable was eliminated (male maxillary third premolar length). Because ME was high and varied considerably across tooth, metric (i.e., length, breadth), and sex, we used the FA10a index. The FA10a index is a measure of the magnitude of FA after parsing ME (Table 2). The total dataset for analysis consisted of nine variables for female breadths, 7 variables for female lengths, nine variables for male breadths, and six variables for male lengths. Table 2 displays the sample size per each variable's FA10a index to provide perspective on statistical power underlying the index.

Table 2: FA10a Index Values for Hypothesis Testing

${ }^{1}$ The sample size from which the FA10 index was created. 
279 Statistical Methods-Data Visualization. Data distributions for all ten replicates and plots of

280

281

282

283

284

285

286

287

288

289

290

291

292

293

294

295

296

297

298

299

300

301

302

303

304

305

306

307

308

309

310

311

312

313

314

315

316

317

318

319

320

321

322

323

324

FA10a were visualized using ggplot2 (Wickham 2016).

Statistical Methods-Hypothesis Testing of Research Questions. Analysis was conducted by $\mathrm{KCH}$ in R v3.6.2 (R Development Core Team, 2008) using R Studio v.1.2.1335 (RStudio Team, 2015). Because FA is a measure of variance about the mean, Levene's test for equality of variance was used to test hypotheses in $\mathrm{R}$ via the leveneTest function in the car package (Fox \& Weisberg 2011). The eruption of upper and lower teeth varies only by a few months in baboon species, which allowed us to pool mandibular and maxillary molars for analysis (Fortman et al. 2002; Hlusko \& Mahaney 2009; Phillips-Conroy \& Jolly 1988; Reed 1973).

\section{RESULTS AND DISCUSSION}

Data Exploration. In humans, FA varies by dimension (e.g., length, breadth), arcade (e.g., mandible, maxilla), and tooth class (e.g., incisor, canine, premolar, molar) (Bailit et al. 1970; Harris \& Nweeia 1980). We explored the data to see if similar trends were apparent in our baboon sample (Table 3 ). We noted above that there are not currently enough data across primate species to understand if FA in non-human primates exhibits the same trends as humans. Our analysis is the first step towards understanding if human trends are visible in our data for olive baboons. There were significant differences in dimensions, with breaths exhibiting lower FA (0.02) and lengths exhibiting higher FA (0.06) — same as in humans (Harris \& Nweeia 1980). There were no significant differences by tooth class or arcade.

\section{Table 3: Data Exploration for FA Trends}

Sex Differences. The first research question is whether there is a sex-based difference in developmental instability. We tested the null hypothesis of no difference. Results indicate there are significant sex-differences in this sample (Table 4), suggesting that males experience greater developmental instability across the period of growth and development. Figure 1 shows the spread of FA10a index values for males and females. Both sexes exhibit greater FA in lengths compared to breadths and males have overall greater variance (FA is a measure of variance), even if some values overlap with females. Mandibular P4 exhibits the most FA in both males and females, but female FA values are almost half that of males.

Figure 1: FA10a values individually by sex (stacked plot, left) and grouped (boxplot by sex, right)

Instability during the weaning period. The second research question is whether weaning is a more stressful time compared to other developmental stages. Due to its developmental timing, the first molar is a likely diagnostic for weaning stress and was expected to have greater variance than the other teeth. FA10a is lower in M1 than other teeth, suggesting weaning is not more stressful compared to other stages of life history (Table 4). There are significant differences between male and female FA10a values, however (Table 4, Figure 2). Both sexes exhibit greater FA in lengths compared to breadths and values for fourth premolars are again the highest (Figure 3)

Peer] reviewing PDF | (2021:02:58413:1:1:NEW 28 Jun 2021) 
328

329

330

331

332

333

334

335

336

337

338

339

340

341

342

343

344

345

346

347

348

349

350

351

352

353

354

355

356

357

358

359

360

361

362

363

364

365

366

367

368

369

Figure 2: FA10a comparing first molar to other teeth (left) and within sex (right)

Instability during the reproductive period. The third research question is whether reproduction is more stressful for females compared to males. We expected female third molars to have greater FA10a values than males and for FA10a to be higher in third molars compared to other teeth. FA10a is lower in M3 than other teeth when sexes are pooled, suggesting that weaning is not more stressful compared to other stages of life history (Table 4). There are significant differences between male and female FA10a values (Table 4, Figure 2). While males have higher FA10a values during reproductive years (based on the third molar developing during this life history stage), both sexes exhibit greater FA in lengths compared to breadths (Figure 3 ).

\section{Figure 3: FA10a comparing third molar to other teeth (left) and within sex (right)}

\section{Table 4: Results of Hypothesis Testing (Levene's Test) \\ CONCLUSION}

We used the FA10a index because it subtracts measurement error from the final index used for hypothesis testing. First, we examined FA across variables (length and breadth measures for individual teeth) to find any trends in FA. The only trend we found was that lengths exhibit more FA than breadths - a trend identified in humans as well (Harris \& Nweeia 1980). Second, we tested hypotheses about developmental instability in different life history phases (i.e., weaning, reproduction).

Sex Differences. Males had greater overall FA values than females, suggesting greater levels of developmental instability. Male baboons have been observed to have relatively shorter and harder lives than females because they leave their birth groups and engage in more violent behavior (e.g., chases, displays) establishing their place in the dominance hierarchy of the new group (Cheney \& Seyfarth 2008). Above and beyond the factors associated with general baboon social structure and hierarchy, males and females have differences in their developmental pathways too. The stability of male developmental pathways may be compromised by several factors. The male fetus stimulates additional maternal antigen production (Lalumière et al. 1999), which may cause male-biased prenatal mortality and other developmental complications (Gualtieri \& Hicks 1985). In addition, elevated testosterone profiles have been associated with immunosuppression (Bradley 1987; Folstad \& Karter 1992; Muehlenbein \& Watts 2010; Roberts et al. 2012), the costs of which range from parasite susceptibility to developmental instability. Given these ontogenetic challenges, males may be more susceptible to external environmental conditions, such as the extremely wet climate and high pathogen exposure during the rainy season that baboons experience at GGNP (Higham et al. 2009). Others have also demonstrated increased FA in marginal or less favorable environments (Bailit et al. 1970; Parsons 1992) and males may be at a disadvantage in these circumstances.

Peer] reviewing PDF | (2021:02:58413:1:1:NEW 28 Jun 2021) 
370 Weaning. FA values were lower in first molars than other teeth, suggesting that weaning is not 371 more stressful compared to other life history stages. Compared to males, however, females had 372 greater overall FA values for the first molar, suggesting a comparatively more stressful time than 373 males during weaning. Mother-infant contact reduces steadily with growth. Mothers reject suckling attempts as early as six months of age but most vigorously when the infant approaches a year (Nash 1978; Rhine et al. 1985). This schedule corresponds with first molar development. For yearling baboons, developmental instability may be linked to weaning stressors which include (a) nutritional stress from decreasing energy availability (Altmann 1998), (b) psychosocial stress from increased separation from the mother (Levine 2005), and (c) physiological stress in the form of decreased pathogen resistance (Katzenberg et al. 1996).

Reproduction. FA values were lower in third molars than other teeth, suggesting that reproduction is not comparatively more stressful than other life history stages. Males, however, had higher third molar FA values than females, suggesting they have a comparatively more stressful time during reproductive years then females. In olive baboons - and a wide range of other primate species - female philopatry and male dispersal is the rule. As mentioned above, baboon males have generally shorter and tougher lives (Cheney \& Seyfarth 2008). There are multiple factors, however, that may compromise the fitness of emigrating individuals. A lone male is more vulnerable to predation (Dunbar 1987) and, as such, spends less time foraging (Slatkin \& Hausfater 1976). Elongated solitary periods of recently matured males also impede their mating prospects. Organisms under such dietary and reproductive stresses expend more energy to counter these challenges (Parsons 1990). The stress associated with male dispersal, both nutritional and psychosocial, may be greater than that of females despite the clear biological burdens of reproduction on the female body. The third molar is the last tooth to develop and has been noted to exhibit greater morphological variation perhaps due to relaxed selective pressurethis might make it more susceptible to the ontogenetic effects of sexual dimorphism (Butler 1939; Gingerich 1974; Mayhall \& Saunders 1986). Third molar length exhibits greater variation than other teeth (Gingerich \& Schoeninger 1979) and the hypoconulid on the distal surface of cercopithecoid mandibular third molars (Swindler 2002) may act to increase variance and asymmetry. Finally, given the negative association (in gorillas) of crown height and FA, we might expect that lower ranked males, who capture a larger share of any sample, would have higher FA from developmental instability, particularly when secondary sexual traits are developing (Manning \& Chamberlain 1994).

Females in our baboon sample have previously been found to have elevated glucocorticoid levels that measure physiological stress (MacLarnon et al. 2015). Our data suggest females exhibit greater instability than males only during weaning. Further, when comparing our data for males to females across all variables, we find that males exhibit greater developmental instability during growth and development than females and developmental instability is highest during early reproductive years. Taking a broader view across life history, we note that our data suggest that reproduction (using M3 FA10 as a proxy) is much more stressful than weaning (using M1 FA10 as a proxy) for both males and females, with mean FA values almost double that for reproduction and almost triple when considering males alone (Figures 2 and 3). Given that male baboons lead relatively harder and tougher lives than females, our findings are in line with the larger understanding of the effect of social structure on health (Cheney \& Seyfarth 2008). Demonstration of FA and the supposition that a group appears under developmental instability 
416 can be relatively straightforward (Leary \& Allendorf 1989), but the identification of a specific

417 stressor remains conjectural. Habitat quality (Manning \& Chamberlain 1994), psychosocial

418 factors (Newell-Morris et al. 1989), diet (Swaddle \& Witter 1994), and social hierarchy (Cheney

419 \& Seyfarth 2008) have all been implicated.

420

421

422

423

424

425

426

427

428

429

430

431

432

433

434

435

436

437

438

439

440

441

442

443

444

445

446

447

448

449

450

451

452

453

454

455

456

457

458

459

\section{FUNDING}

Durham University Learning and Teaching Award

North of England Zoological Society/Chester Zoo

\section{References}

Adanu J, Sommer V, and Fowler A. 2011. Hunters, fire, cattle: conservation challenges in eastern Nigeria, with special reference to chimpanzees. In: Sommer V, and Ross C, eds. Primates of Gashaka: Socioecology and Conservation in Nigeria's Biodiversity Hotspot. New York: Springer, 55-99.

Altmann S. 1998. Foraging for survival: yearling baboons in Africa. Chicago: University of Chicago Press.

Atkinson EG, Rogers J, and Cheverud M. 2016. Evolutionary and developmental implications of asymmetric brain folding in a large primate pedigree. Evolution 70:707-715. 10.1111/evo.12867

Bailit H, Workman P, Niswander J, and MacLean C. 1970. Dental asymmetry as an indicator of genetic and environmental conditions in human populations. Human Biology 42:626-638.

Behrensmeyer AK. 1978. Taphonomic and ecologic information from bone weathering. Paleobiology 4:150-162. 10.1017/S0094837300005820

Boulton RA, and Ross C. 2013. Measuring facial symmetry in the wild: a case study in Olive Baboons (Papio anubis). Behavioral Ecology and Sociobiology 67:699-707. 10.1007/s00265-013-1495-8

Bradley AJ. 1987. Stress and mortality in the red-tailed phascogale, Phascogale calura (Marsupialia: Dasyuridae). General and Comparative Endocrinology 67:85-100. 10.1016/0016-6480(87)90208-5

Butler PM. 1939. Studies of the Mammalian Dentition.-Differentiation of the Post-canine Dentition. Proceedings of the Zoological Society of London B109:1-36. 10.1111/j.14697998.1939.tb00021.x

Cheney DL, and Seyfarth RM. 2008. Baboon Metphysics: The Evolution of a Social Mind. Chicago, IL: University of Chicago Press.

Corruccini RS, and Potter RHY. 1981. Developmental correlates of crown component asymmetry and occlusal discrepancy. American Journal of Physical Anthropology 55:2131.

Corruccini RS, Townsend GC, and Schwerdt W. 2005. Correspondence between enamel hypoplasia and odontometric bilateral asymmetry in Australian twins. American Journal of Physical Anthropology 126:177-182.

Dirks W, and Bowman JE. 2007. Life history theory and dental development in four species of catarrhine primates. Journal of Human Evolution 53:309-320. https://doi.org/10.1016/j.jhevol.2007.04.007 
460 Dirks W, Reid DJ, Jolly CJ, Phillips-Conroy JE, and Brett FL. 2002. Out of the mouths of

461

462

463

464

465

466

467

468

469

470

471

472

473

474

475

476

477

478

479

480

481

482

483

484

485

486

487

488

489

490

491

492

493

494

495

496

497

498

499

500

501

502

503 baboons: Stress, life history, and dental development in the Awash National Park hybrid zone, Ethiopia. American Journal of Physical Anthropology 118:239-252. 10.1002/ajpa.10089

Dunbar RIM. 1987. Demography and reproduction. In: Smuts BB, Cheney DL, Seyfarth RM, Wrangham RW, and Struhsaker TT, eds. Primate Societies. Chicago: University of Chicago Press, 240-249.

Folstad I, and Karter AJ. 1992. Parasites, Bright Males, and the Immunocompetence Handicap. The American Naturalist 139:603-622. 10.1086/285346

Fortman JD, Hewett TA, and Bennett BT. 2002. The Laboratory Nonhuman Primate. Boca Raton: CRC Press.

Fox J, and Weisberg S. 2011. An $\{R\}$ Companion to Applied Regression. Thousand Oaks CA: Sage.

Frederick MJ, and Gallup Jr. GG. 2007. Fluctuating Dental Asymmetry in Great Apes, Fossil Hominins, and Modern Humans: Implications for Changing Stressors during Human Evolution. Acta Psychologica Sinica 39:489-494.

Garn SM, Lewis AB, and Kerewsky RS. 1965. X-linked Inheritance of Tooth Size. Journal of Dental Research 44:439-441. 10.1177/00220345650440022201

Gingerich PD. 1974. Size variability of the teeth in living mammals and the diagnosis of closely related sympatric fossil species. J Paleo 48:895-903.

Gingerich PD, and Schoeninger MJ. 1979. Patterns of tooth size variability in the dentition of primates. American Journal of Physical Anthropology 51:457-465. 10.1002/ajpa.1330510318

Gualtieri T, and Hicks RE. 1985. An immunoreactive theory of selective male affliction. Behavioral and Brain Sciences 8:427-441. 10.1017/S0140525X00001023

Hallgrimsson B. 1993. Fluctuating asymmetry in Macaca fascicularis: A study of the ethiology of developmental noise. International Journal of Primatology 14:421-443.

Harris EF, and Nweeia MT. 1980. Dental asymmetry as a measure of environmental stress in the Ticuna Indians of Columbia. American Journal of Physical Anthropology 53:133-142.

Higham JP, Warren Y, Adanu J, Umaru BN, MacLarnon AM, Sommer V, and Ross C. 2009. Living on the edge: life-history of olive baboons at Gashaka-Gumti National Park, Nigeria. American Journal of Primatology 71:293-304. 10.1002/ajp.20651

Hlusko LJ, and Mahaney MC. 2009. The baboon model for dental development. In: VandeBerg JL, Williams-Blangero S, and Tardif SD, eds. The baboon in biomedical research. New York: Springer, 207-223.

Hoover KC, Corruccini RS, Bondioli L, and Macchiarelli R. 2005. Exploring the relationship between hypoplasia and odontometric asymmetry in Isola Sacra, an Imperial Roman Necropolis. American Journal of Human Biology 17:752-764.

Hoover KC, and Hudson MJ. 2016. Resilience in prehistoric persistent hunter-gatherers in northwest Kyushu, Japan as assessed by population health and archaeological evidence. Quaternary International 405, Part B:22-33. http://dx.doi.org/10.1016/j.quaint.2015.10.047

Jesus G. 2019. Habitat ecology and primate gregariousness in Nigeria's Gashaka Gumti National Park PhD. London, University College of London. 
504 Kahumbu P, and Eley RM. 1991. Teeth emergence in wild olive baboons in Kenya and

505

506

507

508

509

510

511

512

513

514

515

516

517

518

519

520

521

522

523

524

525

526

527

528

529

530

531

532

533

534

535

536

537

538

539

540

541

542

543

544

545

546

547

548

549 formulation of a dental schedule for aging wild baboon populations. American Journal of Primatology $\$ V$ 23:1-9.

Katzenberg M, Herring D, and Saunders S. 1996. Weaning and infant mortality: evaluating the skeletal evidence. Yearbook of Physical Anthropology 39:177-199.

Kelley J, and Schwartz GT. 2010. Dental development and life history in living African and Asian apes. Proceedings of the National Academy of Sciences of the United States of America 107:1035-1040. 10.1073/pnas.0906206107

Kieser J, Groeneveld H, and Preston C. 1986. Fluctuating dental asymmetry as a measure of odontogenic canalization in man. American Journal of Physical Anthropology 71:437444.

Lalumière ML, Harris GT, and Rice ME. 1999. Birth order and fluctuating asymmetry: a first look. Proceedings Biological sciences 266:2351-2354. 10.1098/rspb.1999.0930

Leamy LJ, and Klingenberg CP. 2005. The genetics and evolution of fluctuating asymmetry Annual Review of Ecology Evolution and Systematics 36:1.

Leary RF, and Allendorf FW. 1989. Fluctuating asymmetry as an indicator of stress: Implications for conservation biology. Trends in Ecology \& Evolution 4:214-217. 10.1016/0169-5347(89)90077-3

Leigh SR, and Cheverud JM. 1991. Sexual dimorphism in the baboon facial skeleton. American Journal of Physical Anthropology 84:193-208. 10.1002/ajpa.1330840209

Levine S. 2005. Developmental determinants of sensitivity and resistance to stress. Psychoneuroendocrinology 30:939-946. 10.1016/j.psyneuen.2005.03.013

Little AC, Paukner A, Woodward RA, and Suomi SJ. 2012. Facial asymmetry is negatively related to condition in female macaque monkeys. Behavioral Ecology and Sociobiology 66:1311-1318. 10.1007/s00265-012-1386-4

Lodge E, Ross C, Ortmann S, and MacLarnon AM. 2013. Influence of diet and stress on reproductive hormones in Nigerian olive baboons. General and Comparative Endocrinology 191:146-154. https://doi.org/10.1016/j.ygcen.2013.06.016

MacLarnon AM, Sommer V, Goffe AS, Higham JP, Lodge E, Tkaczynski P, and Ross C. 2015. Assessing adaptability and reactive scope: Introducing a new measure and illustrating its use through a case study of environmental stress in forest-living baboons. General and Comparative Endocrinology 215:10-24. https://doi.org/10.1016/j.ygcen.2014.09.022

Manning JT, and Chamberlain AT. 1993. Fluctuating asymmetry, sexual selection and canine teeth in primates. Proceedings Biological sciences 251:83-87. 10.1098/rspb.1993.0012

Manning JT, and Chamberlain AT. 1994. Fluctuating asymmetry in gorilla canines: a sensitive indicator of environmental stress. Proceedings of the Royal Society of London Series B: Biological Sciences 255:189-193. doi:10.1098/rspb.1994.0027

Markow TA. 1994. Developmental Instability: Its Origins and Evolutionary Implications. Dordrecht: Springer.

Martinez-Gomis J, Lujan-Climent M, Palau S, Bizar J, Salsench J, and Peraire M. 2009. Relationship between chewing side preference and handedness and lateral asymmetry of peripheral factors. Archives of Oral Biology 54:101-107.

10.1016/j.archoralbio.2008.09.006

Mayhall JT, and Saunders SR. 1986. Dimensional and discrete dental trait asymmetry relationships. American Journal of Physical Anthropology 69:403-411. 10.1002/ajpa.1330690311 
550

551

552

553

554

555

556

557

558

559

560

561

562

563

564

565

566

567

568

569

570

571

572

573

574

575

576

577

578

579

580

581

582

583

584

585

586

587

588

589

590

591

592

593

594

595

Muehlenbein MP, and Watts DP. 2010. The costs of dominance: testosterone, cortisol and intestinal parasites in wild male chimpanzees. Biopsychosocial Medicine 4:21. 10.1186/1751-0759-4-21

Nash LT. 1978. The development of the mother-infant relationship in wild baboons (Papio anubis). Animal Behaviour 26:746-759. https://doi.org/10.1016/0003-3472(78)90141-0

Newell-Morris LL, Fahrenbruch CE, and Sackett GP. 1989. Prenatal psychological stress, dermatoglyphic asymmetry and pregnancy outcome in the pigtailed macaque (Macaca nemestrina). Biology of the Neonate 56:61-75. 10.1159/000243104

Nissan J, Gross MD, Shifman A, Tzadok L, and Assif D. 2004. Chewing side preference as a type of hemispheric laterality. Journal of Oral Rehabilitation 31:412-416. 10.1111/j.1365-2842.2004.01256.x

Palmer AR. 1994. Fluctuating Asymmetry Analyses: A Primer. In: Markow TA, ed. Developmental Instability: Its Origins and Evolutionary Implications. Dordrecht, Netherlands: Kluwer, 335-364.

Palmer AR, and Strobeck C. 1986. Fluctuating asymmetry: measurement, analysis, patterns. Annual Review of Ecology and Systematics 17:391-421.

Palmer AR, and Strobeck C. 1992. Fluctuating asymmetry as a mesure of developmental instability: implications of non-normal distributions and powers of statistical tests. Acta Zool Fennica 191:57-72.

Palmer AR, and Strobeck C. 2003a. Fluctuating asymmetry analysis revisited. In: Polak M, ed. Developmental Instability (DI): Causes and Consequences. Oxford: Oxford University Press, 279-319.

Palmer AR, and Strobeck C. 2003b. Fluctuating asymmetry analysis: A step-by-step example. In: Polak M, ed. Developmental Instability: Causes and Consequences. Oxford: Oxford University Press, V1-B36.

Parés Casanova P-M, Lleixà M, Gambo B, Samuel MO, and Olopade J. 2018. Mastication in goats shows a chewing side preference. Animal Husbandry, Dairy and Veterinary Science 2:1-3. https://doi.org/10.15761/AHDVS.1000125.Q

Parés Casanova P-M, and Morros C. 2014. Molar asymmetry shows a chewing-side preference in horses. Journal of Zoological and Bioscience Research 1:14-18. http://hdl.handle.net/10459.1/47480.

Parsons P. 1990. Fluctuating asymmetry: an epigenetic measure of stress. Biological Reviews of the Cambridge Philosophical Society 65:131-145.

Parsons PA. 1992. Fluctuating asymmetry: a biological monitor of environmental and genomic stress. Heredity 68:361-364.

Perzigian AJ. 1981. Allometric analysis of dental variation in a human population. American Journal of Physical Anthropology 54:341-345.

Phillips-Conroy JE, and Jolly CJ. 1988. Dental eruption schedules of wild and captive baboons. American Journal of Primatology 15:17-29. 10.1002/ajp.1350150104

Polak M. 2003. Developmental Instability: Causes and Consequences. Oxford: Oxford University Press.

Reed OM. 1973. Papio cynocephalus age determination. American Journal of Physical Anthropology 38:309-314. 10.1002/ajpa.1330380226

Reeves NM, Auerbach BM, and Sylvester AD. 2016. Fluctuating and directional asymmetry in the long bones of captive cotton-top tamarins (Saguinus oedipus). American Journal of Physical Anthropology 160:41-51. 10.1002/ajpa.22942 
596

597

598

599

600

601

602

603

604

605

606

607

608

609

610

611

612

613

614

615

616

617

618

619

620

621

622

623

624

625

626

627

628

629

630

631

632

633

634

635

636

637

638

639

640

Rhine RJ, Norton GW, Wynn GM, and Wynn RD. 1985. Weaning of free-ranging infant baboons (Papio cynocephalus) as indicated by one-zero and instantaneous sampling of feeding. International Journal of Primatology 6:491. 10.1007/BF02735572

Riga A, Belcastro MG, and Moggi-Cecchi J. 2014. Environmental stress increases variability in the expression of dental cusps. American Journal of Physical Anthropology 153:397-407. 10.1002/ajpa.22438

Roberts ML, Buchanan KL, Goldsmith AR, and Evans MR. 2012. The role of testosterone in bib size determination in the male house sparrow Passer domesticus, is age dependent. Journal of Avian Biology 43:264-272. 10.1111/j.1600-048X.2012.05571.x

Ross C, Warren Y, Maclarnon AM, and Higham JP. 2011. How Different Are Gashaka's Baboons? Forest and Open Country Populations Compared. In: Sommer V, and Ross C, eds. Primates of Gashaka: Socioecology and Conservation in Nigeria's Biodiversity Hotspot. New York, NY: Springer New York, 385-411.

Sarnat B, and Schour I. 1942. Enamel hypoplasia (chronologic enamel aplasia) in relation to systemic disease: A chronologic, morphologic, and etiologic classification. The Journal of the American Dental Association 29:397-418.

Sarnat BG, and Schour I. 1941. Enamel hypoplasia (chronologic enamel aplasia) in relation to systemic disease: A chronologic, morphologic, and etiologic classification. The Journal of the American Dental Association 28:1989-2000.

Sefcek JA, and King JE. 2007. Chimpanzee facial symmetry: a biometric measure of chimpanzee health. American Journal of Primatology 69:1257-1263. 10.1002/ajp.20426

Singleton M. 2002. Patterns of cranial shape variation in the Papionini (Primates: Cercopithecinae). Journal of Human Evolution 42:547-578. https://doi.org/10.1006/jhev.2001.0539

Singleton M, Seitelman BC, Krecioch JR, and Frost SR. 2017. Cranial sexual dimorphism in the Kinda baboon (Papio hamadryas kindae). American Journal of Physical Anthropology 164:665-678. 10.1002/ajpa.23304

Slatkin M, and Hausfater G. 1976. A note on the activities of a solitary male baboon. Primates 17:311-322. 10.1007/BF02382788

Smith TM, Machanda Z, Bernard AB, Donovan RM, Papakyrikos AM, Muller MN, and Wrangham R. 2013. First molar eruption, weaning, and life history in living wild chimpanzees. Proceedings of the National Academy of Sciences of the United States of America 110:2787-2791. 10.1073/pnas.1218746110

Sommer V, and Ross C. 2011. Exploring and protecting West Africa's primates: The Gashaka Primate Project in context. In: Sommer V, and Ross C, eds. Primates of Gashaka: socioecology and conservation in Nigeria's biodiversity hotspot. New York: Springer, 137.

Stafford DK, Milliken GW, and Ward JP. 1993. Patterns of hand and mouth lateral biases in bamboo leaf shoot feeding and simple food reaching in the gentle lemur (Hapalemur griseus). American Journal of Primatology 29:195-207. https://doi.org/10.1002/ajp.1350290305

Swaddle JP, and Witter MS. 1994. Food, Feathers and Fluctuating Asymmetries. Proceedings: Biological Sciences 255:147-152.

Swindler DR. 2002. Primate dentition: an introduction to the teeth of non-human primates. Cambridge: Cambridge University Press.

Peer] reviewing PDF | (2021:02:58413:1:1:NEW 28 Jun 2021) 
641 Ungar PS, Crittenden AN, and Rose JC. 2017. Toddlers in transition: linear enamel hypoplasias

642

643

644

645

646

647

648

649

650

651

652

653

654

655

656

657

658

659

660

661

662

663

664

665

666

667 in the Hadza of Tanzania. International Journal of Osteoarchaeology 27:638-649. 10.1002/oa.2586

Van Valen L. 1962. A study of fluctuating asymmetry. Evolution, the International Journal of Organic Evolution XVI:125-143.

Waddington CH. 1942. Canalization of development and the inheritance of acquired characters. Nature 50:563-565.

Waitt C, and Little AC. 2006. Preferences for Symmetry in Conspecific Facial Shape Among Macaca mulatta. International Journal of Primatology 27:133-145. 10.1007/s10764-0059015-y

Warren Y, Higham JP, Maclarnon AM, and Ross C. 2011. Crop-raiding and Commensalism in Olive Baboons: The Costs and Benefits of Living with Humans. In: Sommer V, and Ross C, eds. Primates of Gashaka: Socioecology and Conservation in Nigeria's Biodiversity Hotspot. New York, NY: Springer New York, 359-384.

Wickham H. 2016. ggplot2: Elegant Graphics for Data Analysis. New York: Springer-Verlag. Willmore KE, Klingenberg CP, and Hallgrímsson B. 2005. The relationship between fluctuating asymmetry and environmental variance in rhesus macaque skulls. Evolution 59:898-909. 10.1111/j.0014-3820.2005.tb01763.x

Zhou L, and Corruccini RS. 1998. Enamel hypoplasias related to famine stress in living Chinese. American Journal of Human Biology 10:723-733.

Zihlman A, Bolter D, and Boesch C. 2004. Wild chimpanzee dentition and its implications for assessing life history in immature hominin fossils. Proceedings of the National Academy of Sciences of the United States of America 101:10541-10543. 10.1073/pnas.0402635101

Zinner D, Buba U, Nash S, and Roos C. 2011. Pan-African voyagers: The phylogeography of baboons. In: Sommer V, and Ross C, eds. Primates of Gashaka: socioecology and conservation in Nigeria's biodiversity hotspot. New York: Springer, 319-358. 


\section{Table $\mathbf{1}$ (on next page)}

ME summary by replicate set 
1 Table 1: ME summary by replicate set

\begin{tabular}{lrrrrrr}
\hline Replicates & ME3 & Mean & Median & Minimum & Maximum & Range \\
$9-10$ & $12 \%$ & $25 \%$ & $22 \%$ & $10 \%$ & $51 \%$ & $41 \%$ \\
$5-6$ & $12 \%$ & $24 \%$ & $22 \%$ & $9 \%$ & $47 \%$ & $38 \%$ \\
$6-9$ & $7 \%$ & $16 \%$ & $16 \%$ & $5 \%$ & $33 \%$ & $29 \%$ \\
$2-5$ & $7 \%$ & $18 \%$ & $16 \%$ & $7 \%$ & $37 \%$ & $30 \%$ \\
$4-7$ & $8 \%$ & $18 \%$ & $15 \%$ & $5 \%$ & $51 \%$ & $46 \%$ \\
$3-8$ & $6 \%$ & $13 \%$ & $12 \%$ & $5 \%$ & $36 \%$ & $31 \%$ \\
$2-9$ & $4 \%$ & $10 \%$ & $9 \%$ & $4 \%$ & $31 \%$ & $27 \%$ \\
$1-10$ & $4 \%$ & $8 \%$ & $8 \%$ & $3 \%$ & $21 \%$ & $18 \%$ \\
\hline
\end{tabular}

2 
Table 2 (on next page)

FA10a Index Values for Hypothesis Testing 
1 Table 2: FA10a Index Values for Hypothesis Testing

\begin{tabular}{|c|c|c|c|c|}
\hline ex & Metric & Tooth & FA10a & $n^{1}$ \\
\hline Female & Breadth & MNM1 & 0.01 & 20 \\
\hline emale & Breadth & MNM2 & 0.01 & 10 \\
\hline emale & Breadth & MNM3 & 0.01 & 20 \\
\hline emale & Breadth & MNP4 & 0.00 & 1 \\
\hline emale & Breadth & MXM1 & 0.01 & 31 \\
\hline emale & Breadth & MXM2 & 0.01 & 50 \\
\hline emale & Breadth & MXM3 & 0.03 & 34 \\
\hline emale & Breadth & MXP3 & 0.04 & 26 \\
\hline emale & Breadth & MXP4 & 0.01 & 31 \\
\hline emale & Length & MNM3 & 0.04 & 20 \\
\hline emale & Length & MNP4 & 0.06 & 15 \\
\hline Gemale & Length & MXM1 & 0.02 & 31 \\
\hline Female & Length & MXM2 & 0.04 & 32 \\
\hline Female & Length & MXM3 & 0.03 & 32 \\
\hline Female & Length & MXP3 & 0.04 & 27 \\
\hline Gemale & Length & MXP4 & 0.05 & 31 \\
\hline Male & Breadth & MNM1 & 0.01 & 17 \\
\hline Male & Bre & MNM2 & 0.03 & 16 \\
\hline Male & Breadth & MNM3 & 0.01 & 14 \\
\hline Male & readth & $\mathrm{MN}$ & 01 & 15 \\
\hline Male & Breadth & MXM1 & 0.01 & 31 \\
\hline Male & Breadth & MXM2 & 0.02 & 34 \\
\hline Male & Breadth & MXM3 & 0.02 & 34 \\
\hline Male & Breadth & MXP3 & 0.03 & 25 \\
\hline Male & Breadth & MXP4 & 0.02 & 29 \\
\hline Male & Length & MNM3 & 0.08 & 14 \\
\hline Male & Length & MNP4 & 0.07 & 15 \\
\hline Male & Length & MXM1 & 0.05 & 33 \\
\hline Male & Length & MXM2 & 0.07 & 35 \\
\hline Male & Length & MXM3 & 0.08 & 33 \\
\hline Male & Length & MXP4 & 0.10 & 29 \\
\hline
\end{tabular}

$2 \frac{1}{1}$ The sample size from which the FA10 index was created. 
Table 3 (on next page)

FA10A Trends 
1 Table 3: FA10a Trends

Model F-value df p-value Sig

$\begin{array}{llll}\text { FA10 Tooth } & 1.78 & 8.00 & 0.14\end{array}$

$\begin{array}{llll}\text { FA10 Class } \quad 0.19 & 1.00 & 0.67\end{array}$

FA10 Arcade $\quad 0.26 \quad 1.00 \quad 0.61$

\begin{tabular}{lllll} 
FA10 Metric & 8.48 & 1.00 & 0.01 & $*$ \\
\hline
\end{tabular}

2

3 
Table 4 (on next page)

Results of Hypothesis Testing (Levene's Test) 
1 Table 4: Results of Hypothesis Testing

\begin{tabular}{lllrrc}
\hline Hypothesis & \multicolumn{1}{c}{ Result } & Model & F & df & p \\
Sex Differences & Significant sex differences & FA10 Sex & 10.602 & 1 & $\mathbf{0 . 0 0 3}$ \\
Weaning & No difference & FA10:M1 Tooth Type & 1.670 & 1 & 0.207 \\
& Significant sex differences & FA10:M1 Tooth Type*Sex & 6.696 & 3 & $\mathbf{0 . 0 0 2}$ \\
Reproduction & No difference & FA10:M3 Tooth Type & 0.064 & 1 & 0.802 \\
& Significant sex difference & FA10:M3 Tooth Type*Sex & 4.313 & 3 & $\mathbf{0 . 0 1 3}$ \\
\hline
\end{tabular}

2

3 
Figure 1

FA10a values individually by sex (stacked plot, left) and grouped (boxplot by sex, right)
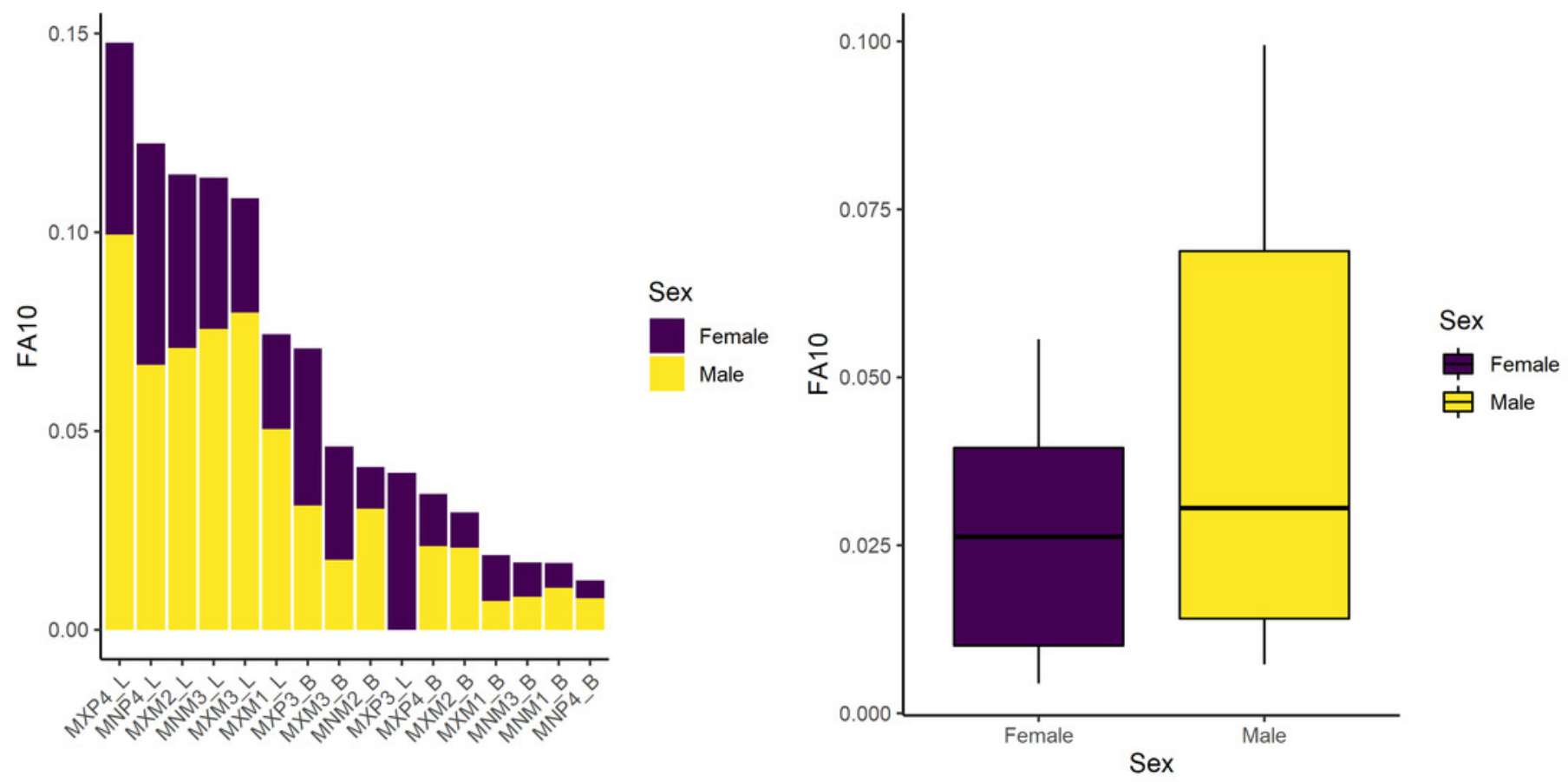
Figure 2

FA10a comparing first molar to other teeth (left) and within sex (right)
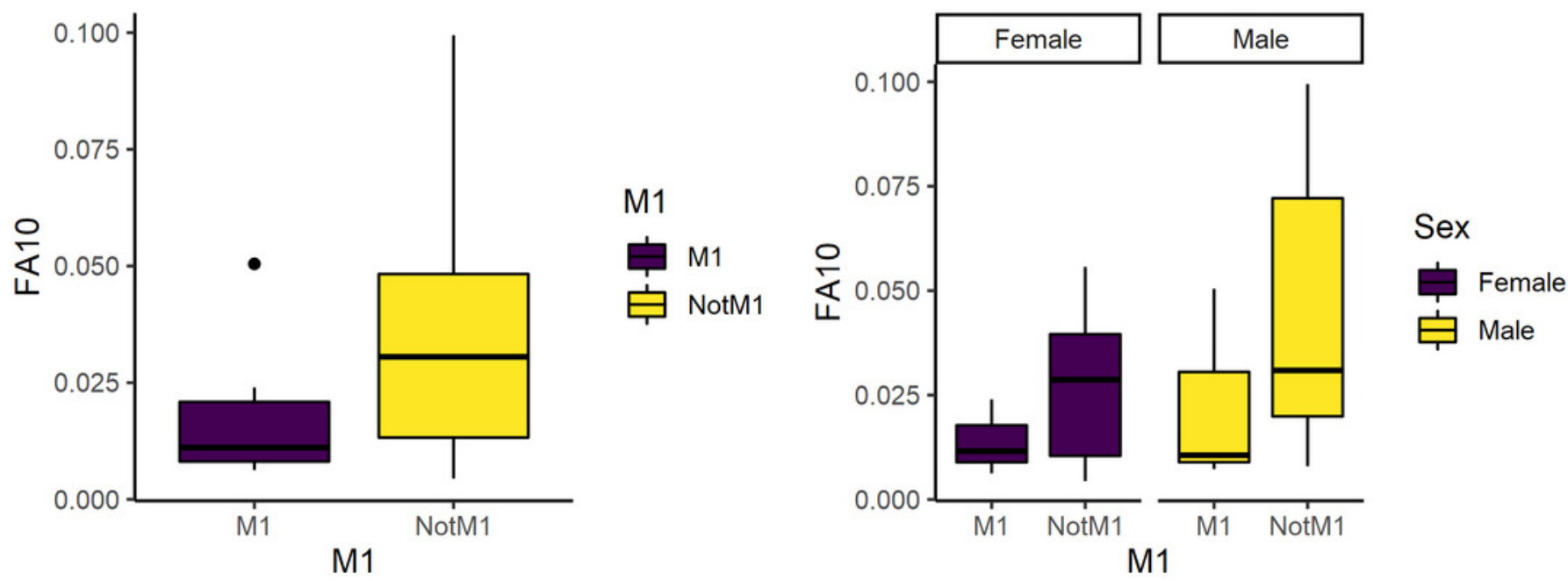
Figure 3

FA10a comparing third molar to other teeth (left) and within sex (right)
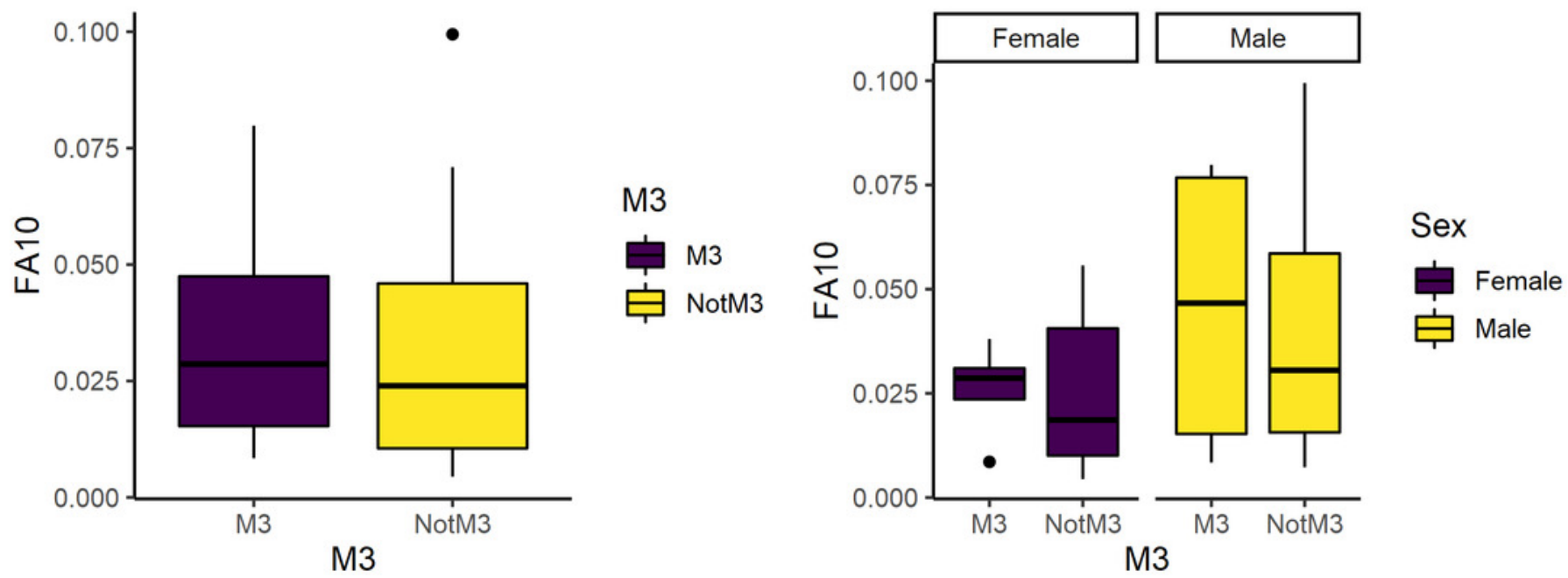